\title{
Bir Hastanede Çalıșan Hemşirelerin Kültürel Duyarlılıkları ile Kültürel Zekaları Arasındaki İlişkinin İncelenmesi
}

\author{
Sinan Aslan ${ }^{1}$, Zeynal Kizir² \\ ${ }^{1}$ Batman Üniversitesi Sağlık Yüksekokulu, Hemşirelik Bölümü, Batman, Türkiye \\ ${ }^{2}$ Adıyaman Üniversitesi Eğitim Araştırma Hastanesi, Adıyaman, Türkiye \\ sinan44aslan@gmail.com, kizir_0234@outlook.com \\ Orcid:0000-0002-2118-5943 \\ Orcid:0000-0003-2669-4883 \\ *Sorumlu Yazar / Corresponding Author: Sinan ASLAN \\ Gönderim Tarihi / Received:14.02.2019 \\ Kabul Tarihi / Accepted: 19.06.2019 \\ DOI: $10.34087 /$ cbusbed.527215
}

\section{$\ddot{O} z$}

\begin{abstract}
Amaç: $\mathrm{Bu}$ araştırma, bir hastanede çalışan hemşirelerin kültürel duyarlılıkları ile kültürel zekaları arasındaki ilişkinin incelenmesi amacıyla yapılmıştır.

Gereç ve Yöntem: Kesitsel olarak planlanan bu araştırma Haziran-Ağustos 2017 tarihleri arasında Adıyaman ilinde bir hastanede yürütülmüştür. Çalışmanın evrenini hastanede çalışan toplam 649 hemşire oluşturmuştur. Araştırmanın örneklemi güç analizine göre, 0.05 yanılgı, 0.95 güven aralığında 0.3 etki büyüklüğünde 0.95 evreni temsil gücüyle 144 hemşire olarak hesaplanmıştır. Veriler, "Tanıtıcı Bilgi Formu", "Kültürlerarası Duyarlılık Ölçeği” ve "Kültürel Zeka Ölçeği” kullanarak toplanmıştır. Verilerin istatistiksel analizinde sayı, yüzdelik değerler ve Pearson korelasyon testi uygulanmıştır. Çalışmanın yapılabilmesi için Adıyaman Üniversitesi Eğitim Araştırma Hastanesinde, Adıyaman Üniversitesi Girişimsel Olmayan Araştırmalar Etik Kurulu'undan etik kurul onayı ve katılımcıların onam izinleri alınmıştır.

Bulgular: Hemşirelerin yaş ortalaması 30.63 \pm 6.74 , Kültürlerarası Duyarlılık Ölçek puan ortalamaları $82.56 \pm 9.38$ ve Kültürel Zeka Ölçek puan ortalaması 99.02 \pm 17.49 'dur. Hemşirelerin \%75.7'si kadın, \%68.1 hemşirelik mesleğini isteyerek seçtiğini, \%51.3'ü kolay iş bulacağından dolayı hemşireliği tercih ettiğini, \%42.4'ü hemşireliğe başladıktan sonra bakış açısının olumlu değiştiğini, \%71.5'i herhangi bir nedenden dolayı başka kültürdeki bireylerle iletişim kurduğunu, \%2.8’i lisans eğitiminde öğrenci değişim programından yararlandığını, \%61.1 yurtdışında hemşire olarak çalışmak istediğini ve \%18.8'i Kültürlerarası hemşirelik konulu panel, sempozyum ve kongreye katıldığını belirtmiştir. Hemşirelerin kültürel duyarlılık ölçek puan ortalamaları ile kültürel zeka ölçek puan ortalamaları arasındaki ilişki pozitif yönden istatistiksel olarak anlamlı bulunmuştur $(r=0.519, \mathrm{p}=0.001)$.

Sonuç: Hemşirelerin kültürel duyarlılıkları artıkça kültürel zekalarının da pozitif yönde artığı saptanmıştır. Sağlık hizmetlerinin istendik seviyeye ulaşabilmesi ve hizmetten yararlanan birey, aile, toplum memnuniyetinin artırılabilmesi için hemşirelerin kültürel duyarlılığının ve kültürel zekalarının farkındalığının artırılması önerilmektedir. Sağlık personellerinin kültürel farkındalığının artırılabilmesi için hizmet içi eğitim programlarında kültürel duyarlılık ve kültürel zeka konularına da yer verilmesi önerilir.
\end{abstract}

Anahtar kelimeler: Kültürel Duyarlılık, Kültürel Zeka, Bakım, Hemşirelik.

\section{Abstract}

Objective: This research was conducted to examine the relationship between cultural sensitivities and cultural intelligences of nurses working in a hospital.

Methods: This descriptive and cross-sectional study was conducted between June and August 2017 in Adiyaman province at a hospital. The universe of the study was consisted by a total of 649 nurses working in the hospital. According to the power analysis, the study sample was calculated as 144 nurses with a representation power of 0.95 universe at a magnitude of 0.3 at an error of 0.05 and a confidence interval of 0.95 . The data were collected using the "Introductory Information Form", the "Cultural Sensitivity Scale" and the "Cultural Intelligence Scale". In the statistical analysis of the data, number and percentage values were applied and Pearson correlation test were applied in independent groups.

Results: The average age of the nurses was $30.63 \pm 6.74$, the Intercultural Sensitivity Scale averages was $82.56 \pm 9.38$ and the Cultural Intelligence Scale averages was $99.02 \pm 17.49$. Of the nurses, $75.7 \%$ were female, 
$68.1 \%$ were choosing nursing profession by research before, $51.3 \%$ were choosing nursing because they would find easy job, and $42.4 \%$ stated that the point of view changed positively after starting nursing. It was stated that $71.5 \%$ of the respondents said that they communicate with other individuals in the culture because of any reason, $2.8 \%$ benefited from student exchange program in undergraduate education, $61.1 \%$ wanted to work as a nurse abroad and $18.8 \%$ participated in panels, symposiums and congresses on intercultural nursing. The relationship between cultural sensitivity scale averages and cultural intelligence scale average scores of nurses was found to be statistically significant $(\mathrm{r}=0.519 \mathrm{p}=0.001)$.

Conclusion: The cultural sensitivities of the nurses were found to increase in the positive direction of cultural intelligences. It is proposed that the awareness of the cultural sensitivity and cultural intelligence of the nurses should be increased so that the health services can reach the desired level and the satisfaction of the individual, the family, the society benefiting from the service can be increased. It is suggested that in-service training programs should include cultural sensitivity and cultural intelligence in order to increase the cultural awareness of health personnel.

Key words: Cultural Sensitivity, Cultural Intelligence, Care, Nursing.

\section{Giriş}

Küreselleşme sonucunda dünyanın her yerindeki kültürleri birbirine yaklaşarak, kültürler arasındaki sınırları ortadan kaldırmış ve kültürlerdeki homojen yapılanmaların değişmesine neden olmuştur. Günümüzde toplumlarının gerek bireysel gerekse de sosyal gruplar bakımından homojen bir nitelik taşıdığını söylemek mümkün değildir [1]. $\mathrm{Bu}$ sebeple kültürlerarası duyarlılık, kültürel farklılıkları anlamaya ve keşfetmeye yönelik pozitif duyguların geliştirilebilmesi olarak tanımlanmakta ve bu doğrultuda kültürlerarası yeterliğin desteklenmesi için bireylerin sahip olmaları gereken birtakım özelliklere dikkat çekmektedir [2]. Bu özellikler; özsayg1, özdenetim, açık fikirlilik, empati, etkileşimli ilişki ve önyargılı ya da peşin hükümlü olmama şeklinde siralanmaktadir $[2,3]$.

Diğer bir yandan küreselleşme ile ortaya çıkan diğer bir kavramda kültürel zekadır. Kültürel zeka, farklı kültürden bir kişinin hareket, davranış, ses, mimik, ton ve vurgusunu, o kişiyle aynı kültürlerden olan bireyler gibi anlayabilmesi, değerlendirilmesi ve yorumlaması olarak ifade edilmektedir [4]. Kültürel zekanın geliştirilmesi farkındalık, bilgi ve davranışlarla devam eden bir süreçtir. Kültürel zeka bireyin önce kendi kültürel kimliğini tanıması, kültürel merceklerini gözden geçirmesi, küresel bir bilinç oluşturması, empati ve iletişim becerilerini geliştirmesiyle ilişsilidir [1,5-7]. Toplumların her geçen gün çok kültürlü yapıya dönüşmesi hemşirelikte kültüre özgü bakımın önemini artırmıştır [8]. Farklı kültürlere sahip olan bireylerin sağlık gereksinimleri de farklılık gösterebilmektedir. Kültürel olarak yeterli bakımın verilebilmesi için hemşirelerin kültürel farkındalık, bilgi ve tecrübeye yani kültürel zekaya ve duyarlılığa sahip olması önemlidir [1,5-7]. Kültürel yönden uygun olan bir bakım hazırlığında olan hemşirenin bireysel olarak kültürel farklılıklar ve benzerlikler hakkında bilgi sahibi olmasını ve duyarlı davranmasını da gerektirir [9] Sağlık bakım sistemi içinde yer alan hemşirelerin kültürlerarası duyarlılığa sahip olmaları beklenmektedir. Çünkü sağlık ve hastalık ile ilgili inançlar ve uygulamalar hemşirelik uygulamalarının içerisinde yer almaktadır [10,11]. Yapılan bir çalışmada, hemşirelerin bakım verdikleri bireylerin kültürlerini tanımalarının ve kültürlerarası duyarlılığa sahip olmalarının hemşirelik bakımına olumlu yansıdığı belirlenmiştir [12]. Bakımda bireyselliğin sağlanması ve sürdürülmesi bireyin holistik olarak değerlendirilmesi ve sorunların çözümlenmesinde girişimlerin bireye özgü planlanarak uygulanması kültürel zeka ile gerçekleştirilebilmektedir. Bireye en uygun olan bakım verilip bakım bireyselleştirildiğinde, bakıma yönelik sonuçların olumlu olduğu [13], hastanın baş etme yeteneğini geliştirdiği [14], bağımlılığını azalttığı ve hastanede kalış süresini kısalttığı görülmüştür [15].

$\mathrm{Bu}$ araştırma, bir hastanede çalışan hemşirelerin kültürel duyarlılıkları ile kültürel zekaları arasındaki ilişkinin incelenmesi amacıyla yapılmıştır.

\section{Gereç ve Yöntem.}

Kesitsel olarak planlanan bu araştırma Haziran-Ağustos 2017 tarihleri arasında Türkiye'nin Güneydoğu Bölgesi'nde yer alan Adiyaman ilinde bir hastanede yürütülmüştür. Çalışmanın evrenini hastanede çalışan toplam 649 hemşire oluşturmuştur. Araştırmanın örneklemi güç analizine göre, 0.05 yanılg1, 0.95 güven aralığında 0.3 etki büyüklüğünde 0.95 evreni temsil gücüyle 144 hemşire olarak hesaplanmıştır. Veriler, "Tanitıcı Bilgi Formu", "Kültürlerarası Duyarlılık Ölçeği (KDÖ)" ve "Kültürel Zeka Ölçeği (KZÖ)", kullanılarak yüz yüze görüşme tekniği ile toplanmıştır.

\subsection{Kültürel Duyarlılık Ölçeği,}

5'li likertli tipte olup 24 maddeden oluşmaktadır. Chen ve Staros ${ }^{\text {ee }}$ ta tarafindan geliştirilmiş ve Türkçe geçerlilik ve güvenirliği Bulduk ve arkadaşları tarafından yapılan KDÖ, 5'li likertli (kesinlikle katılmiyorum (1), katılmıyorum (2), kararsızım (3), katıliyorum (4) ve kesinlikle katıliyorum (5)) tipe sahiptir ve beş duygusal alt boyutta oluşmaktadır. Ölçeğin iletişimde sorumluluk boyutu $1,11,13,21,22,23$ ve 24 . maddelerden, kültürel farklılıklara saygı boyutu 2, 7, 8,16, 18 ve 20 . maddelerden, iletişimde kendine güvenme boyutu 3, 4, 5,6 ve 10. maddelerinden, iletişimden hoşlanma boyutu 9, 12 ve 15. maddelerinden, iletişimde dikkatli olma boyutu 14,17 ve 19 . maddelerinden oluşmaktadır. Ölçeğin $2,4,7,9,12,15,18,20$ ve 22. maddeleri ters olarak kodlanmaktadır. Ölçekte en az 24, en fazla 120 puan alınmaktadır [2]. 


\subsection{Kültürel Zeka Ölçeği}

(KZÖ), 7'li likertli tipte olup, bilişsel, üst bilişsel, davranışsal ve motivasyonel olarak dört alt boyutta ve 20 maddeden oluşmaktadır. KZÖ'den en az 20, en fazla 140 alınmaktadır [16]. Ölçek puan ortalamaları artıkça kültürel duyarlılık düzeyi ve kültürel zeka düzeyi artmaktadır.

Verilerin istatistiksel analizinde sayı, yüzdelik değerler ve Pearson korelasyon testi uygulanmıştır.

\subsection{Araştırmanın Etik Yönü}

Araştırmanın uygulanabilmesi için Adıyaman Üniversitesi Girişimsel Olmayan Araştırmalar Etik Kurulu'ndan etik kurul izin alınmıştır (2017-7/30). Adıyaman Üniversitesi Eğitim Araştırma Hastanesi'nde çalışmanın yapılabilmesi için yazılı izin alınmıştır. Araştırmaya kendi rızasıyla katılan Adıyaman Üniversitesi Eğitim Araştırma Hastanesi'nde çalışan hemşirelerden yazılı onam alınmıştır. Araştırmada veri toplama formlarına hemşirelerden isimlerini/soyisimlerini yazmamaları istenmiş ve çalışmanın gizliliği sağlanmıştır.

\section{Bulgular}

Katılımcıların yaş ortalaması $30.63 \pm 6.74$ ve çalışma yılı ortalaması 9.02 \pm 6.64 'dür. Hemşirelerin \%75.7'si kadın, $\% 68.1$ 'i hemşirelik mesleğini isteyerek seçtiğini, \%51.3'ü hemşirelik mesleğini kolay iş bulma nedeniyle tercih ettiğini, \%82.6's1 uzun süre il merkezinde yaşadığını, \% 47.2'si yaşadığı mesleki deneyimler sonucunda hemşirelik mesleğine bakış açısı olumsuz değiştiğini, \%71.5'i başka kültürden insanlar ile birlikte olma firsatı bulduğunu, \%46.5'i herhangi bir yabancı dil bilmediğini, \%2.8'i öğrencilik döneminde yurtdışı deneyimi yaşadığını, \%18.8'i kültürlerarası hemşirelik konulu panel, sempozyum veya toplantıya katıldığını ve \%61.1'i hemşire olarak yurtdışında çalışmak istediğini belirtmiştirler (Tablo 1).

Tablo 2' yi incelediğimizde hemşirelerin KDÖ puan ortalaması $82.56 \pm 9.38$ olarak saptanmış olup hemşirelerin kültürel düzeyleri oldukça yüksek bulunmuştur (Tablo 2).

Tablo 3'ü incelediğimizde hemşirelerin KZÖ puan ortalaması $99.02 \pm 17.50$ olarak saptanmış olup hemşirelerin kültürel düzeyleri oldukça yüksek bulunmuştur (Tablo 3).

KZÖ ve KDÖ’den alınan puanlar arasındaki ilişki Tablo 4'te verilmiştir. Kültürel Zeka Ölçeği toplam puanı ile Kültürel Duyarlılık Ölçeği toplam puanı, KZÖ üst bilişsel alt boyutu ile KDÖ toplam puanı, iletişimde sorumluluk, iletişimde kendine güven, iletişimde hoşlanma, iletişimde dikkatli olma alt boyutları arasında; KZÖ bilişsel alt boyutu ile KDÖ toplam puanı, iletişimde kendine güven, iletişimde dikkatli olma alt boyutları arasında; KZÖ motivasyonel alt boyutu ile KDÖ toplam puanı ve iletişimde sorumluluk, iletişimde kendine güven ve iletişimde dikkatli olma alt boyutları arasında; KZÖ davranışsal alt boyutu ile KDÖ toplam puanı, iletişimde sorumluluk, iletişimde kendine güven, iletişimde hoşlanma, iletişimde dikkatli olma alt boyutları arasında; arasında pozitif yönlü bir ilişki belirlenmiştir $(\mathrm{p}<0.05)$ (Tablo 4).

Tablo 1: Katılımcılara ait tanıtıcı bilgilerin dağılımı

\begin{tabular}{|c|c|c|}
\hline Tanıtıcı özellikler & $\mathbf{n}$ & $\%$ \\
\hline $\begin{array}{l}\text { Cinsiyet } \\
\text { Erkek } \\
\text { Kadın }\end{array}$ & $\begin{array}{c}35 \\
109\end{array}$ & $\begin{array}{l}75.7 \\
24.3\end{array}$ \\
\hline $\begin{array}{l}\text { Hemșirelik mesleğini } \\
\text { tercih etme durumu } \\
\text { İsteyerek } \\
\text { İstemeyerek }\end{array}$ & $\begin{array}{l}98 \\
46\end{array}$ & $\begin{array}{l}68.1 \\
31.9\end{array}$ \\
\hline $\begin{array}{l}\text { Hemșirelik mesleğini } \\
\text { seçme nedeni } \\
\text { Kolay iş bulma(ekonomik } \\
\text { nedenler } \\
\text { İstediği meslek olması } \\
\text { Ailenin isteği } \\
\text { Öğretmenin isteği } \\
\text { Diğer }\end{array}$ & $\begin{array}{c}74 \\
34 \\
26 \\
4 \\
6\end{array}$ & $\begin{array}{c}51.3 \\
23.6 \\
18.1 \\
2.8 \\
4.2\end{array}$ \\
\hline $\begin{array}{l}\text { Uzun süre yașadığı } \\
\text { Metropol il, ilçe } \\
\text { Köy } \\
\text { Yurtdışı }\end{array}$ & $\begin{array}{c}119 \\
25 \\
0\end{array}$ & $\begin{array}{c}82.6 \\
17.4 \\
0.0\end{array}$ \\
\hline $\begin{array}{l}\text { Yașadığı denevimler } \\
\text { sonucu } \quad \text { hemşirelik } \\
\text { mesleğine bakıș acısı } \\
\text { Olumlu değişti } \\
\text { Olumsuz değişti } \\
\text { Hiç değişmedi }\end{array}$ & $\begin{array}{l}61 \\
68 \\
15\end{array}$ & $\begin{array}{l}42.4 \\
47.2 \\
10.4\end{array}$ \\
\hline $\begin{array}{l}\text { Bașk kișilerle birlikte } \\
\text { olma firsatı } \\
\text { Evet } \\
\text { Hayır }\end{array}$ & $\begin{array}{c}103 \\
41\end{array}$ & $\begin{array}{l}71.5 \\
28.5\end{array}$ \\
\hline $\begin{array}{l}\text { Yabancı dil bilme düzeyi } \\
\text { İleri düzey } \\
\text { Orta düzey } \\
\text { Başlangıç } \\
\text { Hiç bilmiyor }\end{array}$ & $\begin{array}{c}3 \\
31 \\
43 \\
67\end{array}$ & $\begin{array}{l}2.1 \\
21.5 \\
29.9 \\
46.5\end{array}$ \\
\hline $\begin{array}{l}\text { Öğrencilik döneminde } \\
\text { yurtdıș deneyimi } \\
\text { Evet } \\
\text { Hayır }\end{array}$ & $\begin{array}{c}4 \\
140\end{array}$ & $\begin{array}{c}2.8 \\
97.2\end{array}$ \\
\hline $\begin{array}{l}\text { Kültürlerarası hemsirelik } \\
\text { konulu sempozyum, panel } \\
\text { veya toplantıya katılma } \\
\text { durumu } \\
\text { Evet } \\
\text { Hayır }\end{array}$ & $\begin{array}{c}27 \\
117\end{array}$ & $\begin{array}{l}18.8 \\
81.2\end{array}$ \\
\hline 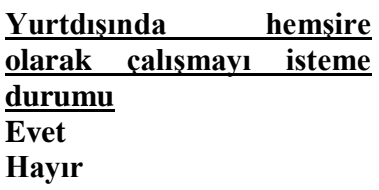 & $\begin{array}{l}88 \\
56\end{array}$ & $\begin{array}{l}61.1 \\
38.9\end{array}$ \\
\hline
\end{tabular}


Tablo 2: Kültürel duyarlılık ölçeğinin alt boyutları ve toplam puanlarının incelenmesi

\begin{tabular}{|l|c|c|}
\hline Alt boyut & $\mathbf{X} \pm \mathbf{S S}$ & Min- max \\
\hline İletişimde sorumluluk & $25.56 \pm 4.56$ & $14-52$ \\
\hline $\begin{array}{l}\text { Kültürel farklııklara } \\
\text { saygı duyma }\end{array}$ & $17.60 \pm 2.99$ & $8-24$ \\
\hline $\begin{array}{l}\text { İletişimde kendine } \\
\text { güven }\end{array}$ & $16.98 \pm 3.04$ & $5-25$ \\
\hline İletişimde hoşlanma & $7.04 \pm 2.31$ & $3-15$ \\
\hline İletişimde dikkatli olma & $15.39 \pm 3.27$ & $3-21$ \\
\hline Toplam & $82.56 \pm 9.38$ & $50-111$ \\
\hline
\end{tabular}

Tablo 3. Kültürel zeka ölçeğinin alt boyutları ve toplam puanlarının incelenmesi

\begin{tabular}{|l|c|c|}
\hline Alt boyut & $\mathbf{X} \pm \mathbf{S S}$ & Min- max \\
\hline Üstbilişsel & $22.10 \pm 4.48$ & $7-28$ \\
\hline Bilişsel & $24.40 \pm 7.20$ & $7-48$ \\
\hline Motivasyonel & $26.47 \pm 5.61$ & $11-35$ \\
\hline Davranış & $26.04 \pm 6.05$ & $5-35$ \\
\hline Toplam & $99.02 \pm 17.50$ & $51-140$ \\
\hline
\end{tabular}

Tablo 4. Kültürel zeka ölçeğinin alt boyutları ile Kültürel duyarlılık ölçek alt boyutları arasındaki ilişki

\begin{tabular}{|c|c|c|c|c|c|c|c|}
\hline & & \multicolumn{6}{|c|}{ Kültürrel duyarlılık ölçeği } \\
\hline Kültürel zeka ölçeği & & $\begin{array}{l}\text { İlişkide } \\
\text { sorumluluk }\end{array}$ & $\begin{array}{c}\text { Kültürel } \\
\text { farklılıklara } \\
\text { saygı duyma }\end{array}$ & $\begin{array}{c}\text { İletişimde } \\
\text { kendine güven }\end{array}$ & $\begin{array}{l}\text { İletişimde } \\
\text { hoşlanma }\end{array}$ & $\begin{array}{c}\text { İletişimde } \\
\text { dikkatli olma }\end{array}$ & Toplam \\
\hline Üst bilişsel & $\begin{array}{l}\mathrm{r} \\
\mathrm{p}\end{array}$ & $\begin{array}{l}.332 \\
.001\end{array}$ & $\begin{array}{l}0.80 \\
.340\end{array}$ & $\begin{array}{c}.43 \\
.001 *\end{array}$ & $\begin{array}{l}-.190 \\
.020^{*}\end{array}$ & $\begin{array}{l}.461 \\
.001^{*}\end{array}$ & $\begin{array}{l}.440 \\
.001 *\end{array}$ \\
\hline Bilişsel & $\begin{array}{l}\mathrm{r} \\
\mathrm{p}\end{array}$ & $\begin{array}{l}.43 \\
.612\end{array}$ & $\begin{array}{l}.021 \\
.800\end{array}$ & $\begin{array}{l}.178 \\
.03^{*}\end{array}$ & $\begin{array}{l}.038 \\
.651\end{array}$ & $\begin{array}{c}.395 \\
.0001^{*}\end{array}$ & $\begin{array}{l}.232 \\
.005^{*}\end{array}$ \\
\hline Motivasyonel & $\begin{array}{l}\mathrm{r} \\
\mathrm{p}\end{array}$ & $\begin{array}{l}.327 \\
.001 *\end{array}$ & $\begin{array}{l}.112 \\
.182\end{array}$ & $\begin{array}{l}.380 \\
.001^{*}\end{array}$ & $\begin{array}{l}-.139 \\
.096\end{array}$ & $\begin{array}{l}.650 \\
.001^{*}\end{array}$ & $\begin{array}{c}.51 \\
.001 *\end{array}$ \\
\hline Davranışsal & $\begin{array}{l}\mathrm{r} \\
\mathrm{p}\end{array}$ & $\begin{array}{l}.156 \\
.06 *\end{array}$ & $\begin{array}{l}.056 \\
.507\end{array}$ & $\begin{array}{l}.250 \\
.003 *\end{array}$ & $\begin{array}{l}-.173 \\
.038^{*}\end{array}$ & $\begin{array}{l}.860 \\
.001 *\end{array}$ & $\begin{array}{l}.430 \\
.001 *\end{array}$ \\
\hline Toplam & $\begin{array}{l}\mathrm{r} \\
\mathrm{p}\end{array}$ & $\begin{array}{l}.259 \\
.002 *\end{array}$ & $\begin{array}{l}.084 \\
.316\end{array}$ & $\begin{array}{l}.390 \\
.001\end{array}$ & $\begin{array}{l}-.137 \\
.102\end{array}$ & $\begin{array}{l}.788 \\
.001 *\end{array}$ & $\begin{array}{l}.519 \\
.001\end{array}$ \\
\hline
\end{tabular}

\section{Tartışma}

Hemşirelerin yeterli düzeyde kültürel yeterliliğe sahip olması bakım verdiği birey, aile, toplum ve çalıştığ kurumun sağlık çıktılarının iyileştirilmesini sağlamak ile birlikte kuruma duyulan memnuniyetin artmasına da neden olmaktadır $[17,18]$.

$\mathrm{Bu}$ çalışmada, hemşirelerin kültürel duyarlılık ölçeği puan ortalaması $82.56 \pm 9.38$ olarak saptanmış olup hemşirelerin kültürel düzeyleri oldukça yüksek bulunmuştur. Aslan ve arkadaşlarının yaptıkları çalışmada hemşirelik öğrencilerinin KDÖ puan ortalamaları 77,81 \pm 8.86 olarak hesaplanmıştır [19]. Bulduk ve arkadaşlarının yaptıkları çalışma öğrencilerin KDÖ'den aldıkları toplam puan $88,94 \pm 14,12$ olarak bulundu ve bu düzey orta altı olarak değerlendirilmiştir [20]. Meydanlıoğlu ve arkadaşlarının yaptıkları çalışmada, hemşirelik ve tıp öğrencilerin kültürel duyarlılık düzeylerinin yüksek olduğunu belirlemiştir [21].

Hemşireler, kültürel zekaları sayesinde kritik durumlarda doğru kararlar verebilir, iş arkadaşlarıyla sağlıklı ekip çalışması kurabilir ve hastalarıyla etkin iletişime geçerek verdikleri bakım uygulamaları ile hasta memnuniyetini arttırabilirler [22]. Bu çalışmada hemşirelerin KZÖ puan ortalaması 99.02 \pm 17.50 olarak saptanmış olup, hemşirelerin kültürel düzeyleri yüksek bulunmuştur. Kant ve Ünal'ın yaptıkları çalışmada hemşirelerin kültürel zekalarının $90.79 \pm 18.70$ olarak saptamışlardır [23]. Güner ve arkadaşlarının Van'da hemşirelik öğrencileri ile yaptıkları çalışmada öğrencilerin kültürel zeka ölçek puan ortalamalarını 93.94 \pm 20.09 olarak belirlemişlerdir [18]. Diğer çalışmalara göre bizim çalışmamızdaki hemşirelerin KZÖ puan ortalamaları daha yüksek bulunmuştur.

Kültürel zekası yüksek bireyler daha kolay uyum sağlamakta ve farklı kültürdeki bireyler ile daha kolay iletişim kurabilmektedirler. Yüksek kültürel zekaya sahip olabilmek ve bu zekayı geliştirmek için istekli ve sabırlı olmak çok önemlidir [24,25]. Bu çalışmada KZÖ toplam puanı ile KDÖ toplam puanı, KZÖ üst bilişsel alt boyutu ile KDÖ toplam puanı, ilişkide sorumluluk, 
kendine güven, iletişimde hoşlanma, iletişimde dikkatli olma alt boyutları arasında; KZÖ bilişsel alt boyutu ile KDÖ toplam puanı, ilişkide kendine güven iletişimde dikkatli olma alt boyutları arasında; KZÖ motivasyonel alt boyutu ile KDÖ toplam puanı ve ilişkide sorumluluk, kendine güven ve iletişimde dikkatli olma alt boyutları arasında; KZÖ davranışsal alt boyutu ile KDÖ toplam puanı, ilişkide sorumluluk, kendine güven, iletişimde hoşlanma, iletişimde dikkatli olma alt boyutları arasında; arasında pozitif yönlü bir ilişki belirlenmiştir $(p<0.05)$. Mercan'ın konaklama işletmelerinde çalışanlar ile yaptığı çalışmada kültürel zekâ alt boyutlarından bilişsel boyut, davranışsal boyut, üstbilişsel boyut, motivasyonel boyut ile kültürler arası duyarlılık boyutlarından kültürel iletişimde sorumluluk boyutu, kültürler arası farklılıklara saygı boyutu, etkileşimde kendine güvenme boyutu görüşleri arasında istatistiksel olarak anlamlı bir ilişki bulunmuştur [1]. İlhan ve Çetin'in Eğitim Fakültesi öğrencilerinde yaptıkları çalışmada kültürel zeka ile kültürel duyarlılık arasında istatistiksel olarak anlamlı ve pozitif yönde bir ilişki bulduklarını belirtmişlerdir $(\mathrm{r}=.61 \mathrm{p}<0.001)$ [16].

Kültürel zekanın bireyin diğer insanlar ile etkileşime girme kapasitelerine odaklandıkları ve dolayısıyla birbirileri ile ilişkili yapılar olduklarının desteklemektedir [26]. Literatür ile bizim çalışmamızın sonuçları paralellik göstermektedir. Kültürel zeka kültürel duyarlılığı, kültürel duyarlılıkta kültürel zekayı etkilemektedir.

\section{Sonuc}

Sonuç olarak hemşirelerin kültürel duyarlılıkları yüksek düzeyde ve kültürel zekaları ise orta düzeyde bulunmuştur. Hemşirelerin kültürel duyarlılıkları ile kültürel zekalar arasında pozitif yönde orta düzeyde ilişki saptanmıştır. Hemşirelerin profesyonel ve bütüncül bakım verebilmeleri için hemşirelerin kültürel zeka ve kültürel duyarlılık becerilerine sahip olması büyük önem taşımaktadır. Bu nedenle hemşirelerin bu kavramlarla ilgili farkındalığının artırılması, kültürel duyarlılık ve kültürel zekâ özelliklerinin yükseltilmesinin önemli olduğu düşünülmektedir. Sağlık hizmetlerinin istendik seviyeye ulaşabilmesi ve hizmetten yararlanan birey, aile, toplum memnuniyetinin artırılabilmesi için hemşirelerin kültürel duyarlılığının ve kültürel zekalarının farkındalığının artırılması önerilmektedir. Sağlık personellerinin kültürel farkındalığının artırılabilmesi için hizmet içi eğitim programlarında kültürel duyarlılık ve kültürel zeka konularına da yer verilmesi önerilebilinir.

\section{Referanslar}

1. Mercan, N, Çoklu kültürler ortamda kültürlerarası duyarlılık ile ilişkine yönelik bir çalışma, Niğde Üniv. İkdisadi ve İdari Bilimler Fakültesi Dergisi, 2016, 9(1), 1-13.

2. Bulduk, S, Tosun, H, Ardıç, E, Türkçe kültürlerarası duyarlılık ölçeğinin hemşirelik öğrencilerinden ölçümsel özellikleri, Türkiye Klinikleri J. Med. Ethics, 2011, 19(1), 25-31.

3. Chen, G, A review of the concept of intercultural sensitivity, Paper Presented at the Biennial Convention Of Pacific and
Asian Communication Association, January, 1997. Honolulu, Hawaii.

4. Earley, P.C, Mosakowski, E, Cultural Intelligence. Harvard Business Review, 2004, 82(10), 139-46.

5. Şahin, F, Liderin Kültürel zekâsının astların örgütsel vatandaşlık davranıșı ile iș doyumu üzerine etkisi, Savunma Bilimleri Dergisi, 2011, 10(2), 83-84.

6. Asunakutlu, T, Safran, B, Kültürel farklılıklardan kaynaklanan çatışmalara yönelik bir araştırma (Marmaris turizm sektörü örneği), Dokuz Eylül Üniversitesi Sosyal Bilimler Enstitüsü Dergisi, 2004, 6(1), 26-49.

7. Okanlı, A, Kültürel Zeka. Journal of Human Sciences, 2017,14(4),30

8. Bilgen, F.G, Çam, H.H, Korkmaz, A.Ç, Şekeroğlu, Ş, Karasu, F, Çok kültürlü ortamlarda hemşirelik bakımında kültürel zekanın önemi, Journal of Human Sciences ,2017, 14(4), 333.

9. Öztürk, E, Öztaş, D, Transkültürel hemşirelik, Batman University Journal of Life Sciences, 2012, 1(1), 293-300.

10. Narayanasamy, A, Transcultural nursing: how do nurses respond to cultural needs?, British Journal of Nursing, 2003, 12, 185-194

11. Şahin, N.H, Bayram, G, Avcı, D, Kültürel duyarlı yaklaşım: transkültürel hemşirelik, Hemşirelikte Eğitim ve Araştırma Dergisi, 2009, 6, 2-7.

12. Hisama, K.K, Cultural influence on nursing scholarship and education, Nursing Outlook. 2000, 48, 128-131.

13. Suhonen, R, Schmidt, L. A, Radwin, L, Measuring individualized nursing care: Assessment of reliability and validity of three scales. Journal of Advanced Nursing, 2007, 59(1), 77-85.

14. Suhonen, R, Land, L, Valimaki, M, Berg, A, Idwall, E., Kalafati, M, Katajisto, J, Lemonidou, C, Schmidt, L.A, LeinoKilpi, H, Impact of patient characteristics on orthopaedic and trauma patients' perceptions of individualised nursing care, International Journal of Evidence-Based Healthcare, 2010, 8, 259-267.

15. Suhonen, R, Valimaki, M, Leino-Kilpi, H, Individualized care from patients', nurses' and relatives' perspective review of the literature, nternational Journal of Nursing Studies, 2002, 39, 645-654.

16. İlhan ,M, Çetin, B, Kültürel Zekâ Ölçeği'nin Türkçe formunun geçerlik ve güvenirlik çalışması, Hacettepe Üniversitesi Eğitim Fakültesi Dergisi, 2014, 9(2), 94-114.

17. Tanrıverdi, G, Hemşirelerde Kültürel Yeterliliği Geliştirme Yaklaşım ve Önerileri. Eds: H. Ülker, C. Birkök. Birinci Baskı. ÇOMÜ Yayınları. Yayın No:131. Birkök. Pozitif Matbaa 2016.

18. Tanrıverdi, G. Hemşirelikte yeni bir model önerisi: Çevre odaklı kültürel yeterlilik modeli, Journal of Human Sciences, 2017, 14(4), 4658-4670.

19. Aslan, S, Yılmaz, D, Kartal, M, Erdemir, F, Güleç, H.Y. Determination of Intercultural Sensitivity of Nursing Students in Turkey. İnternational Journal of Health Sciences and Research, 2016, 6(11), 202-208.

20. Bulduk, S, Usta, E, Dinçer, Y, Kültürlerarası Duyarlılık ve Etkileyen Faktörlerin Belirlenmesi: Bir Sağlık Hizmetleri Meslek Yüksekokulu Örneği, Düzce Üniversitesi Sağlık Bilimleri Enstitüsü Dergisi 2017, 7 (2), 73-77.

21. Meydanlığlu, A, Arıkan, F, Gözüm, S, Cultural sensitivity levels of university students receiving education in health disciplines, Adv Health Sci Educ Theory Pract. 2015, 20(5), 1195-204.

22. Çolak Okumuş ,D, Uğur, E, Hemşirelerin duygusal zeka düzeylerinin bakım davranışlarına etkisi, ACU Sağlık Bilimleri Dergisi 2017, (2), 104-09.

23. Kant, E, Sevgi Ünal, K, Hemşirelerde Kültürel Zekanın Bireyselleştirilmiş Bakım Üzerine Etkisi. Journal of Human Sciences, 2017, 14(4), 113-118.

24. Güner, İ, Karaaslan, S, Orhun, R, Ulay, G, Van sağlık yüksekokulu öğrencilerinin kültürel zekaları ile memnuniyet duyguları arasındaki ilişki Journal of Human Sciences, 2017, 14(4), 337-38

25. Başoğul, C, Hemşirelikte kültürel zekanın önemi ve etkileyen faktörler. Journal of Human Sciences ,2017, 14(4), 402-403.

26. Thomas, D.C, Elron ,E, Stahl, G, Ekelund, B.Z, Ravlin, R.C, Cerdin, J, Cultural intelligence: Domian assessment. 
International Journal of Cross Cultural management 2008, $8(2), 123-43$

http://edergi.cbu.edu.tr/ojs/index.php/cbusbed isimli yazarın CBU-SBED başlıklı eseri bu Creative Commons Alınt1-Gayriticari4.0 Uluslararası Lisansı ile lisanslanmıștır.

(c) $($ ) 8 